\title{
Chronobiology and the case for sleep health interventions in the community
}

\author{
Hatta Santoso Ong ${ }^{1,2}$, MBBS, MRCPsych, Chau Sian $\underline{\text { Lim }}^{1,2}$, MMed, FAMS, Ai-Li Constance Png ${ }^{2,3}$, BSocSci(Hons), MClinPsych, \\ Jing Wen Kong ${ }^{4}$, mmed, fams, Andrew Lai Huat $\underline{P e h}^{1}$, MMed, Fams
}

\begin{abstract}
Our sleep-wake cycle is determined by the interaction between our homeostatic sleep drive and circadian rhythm. Each of us has a personalised biological rhythm or chronotype that determines the optimal time to fall asleep and wake up. Chronic sleep deprivation has been linked to the development of several physical and mental health disorders, as well as accidents and occupational errors. Around the world, growing recognition of the importance of sleep has led to the adoption of practices that promote sleep health. Given that Singaporeans were consistently found to be one of the most sleep-deprived populations in the world, we believe that there is an urgent need to pursue the introduction of community-based sleep health interventions here. This includes sleep education and promotion of sleep hygiene, adopting practices to reduce social jetlag and improve sleep health, and enhancing screening and treatment of sleep disorders.
\end{abstract}

Keywords: chronobiology, circadian rhythm, sleep deprivation, sleep health, sleep hygiene

\section{INTRODUCTION}

Virtually all of us are innately cognisant of the importance of sleep. However, the daily sleep-wake cycles of many individuals are no longer driven by the light and dark cycle, but by work schedules, economic interests and increasing globalisation. With multiple role demands and expectations, sleep is often considered an expendable luxury. This article aims to inform the reader about human chronobiology, the importance of sleep and the consequences of sleep deprivation. We also discuss and examine possible sleep health interventions in the community, including the role of the primary care physician.

\section{HUMAN CHRONOBIOLOGY}

The human sleep-wake cycle is determined by the homeostatic sleep drive and the circadian rhythm. ${ }^{(1)}$ The interaction between these two processes has been conceptualised in the 'two-process model of sleep'..$^{(2,3)}$ The homeostatic process (Process S) involves an increasing sleep drive that accumulates during our waking hours and dissipates during sleep. The circadian rhythm (Process $\mathrm{C}$ ) is an internal biological clock that regulates our subjective alertness, performance levels, core body temperature and hormonal rhythms, such as that of cortisol. The major circadian pacemaker in humans is the suprachiasmatic nucleus $(\mathrm{SCN})$ in the hypothalamus of the brain. The SCN relies on a combination of internal and external cues for its rhythm. Light exposure is the primary external cue, or zeitgeber, ${ }^{(4)}$ for this circadian pacemaker. The circadian regulation of sleep creates a drive for wakefulness during the day, which then declines at night. ${ }^{(5,6)}$ Each of us has a personalised biological rhythm or chronotype that determines the optimal time to fall asleep and wake up.

\section{SLEEP AND SLEEP HEALTH}

In recent decades, increased research into sleep medicine has resulted in greater awareness and understanding of the effects of sleep on both physical and mental health. Sleep serves several important functions. It helps to maintain cognitive functions, such as attention, processing speed, executive function and memory. ${ }^{(7-9)}$ Sleep plays a role in the maintenance of the immune system ${ }^{(10)}$ and also encourages body restoration, ${ }^{(11)}$ growth and repair. It is also believed that sleep clears the brain of metabolic waste via the glymphatic system. ${ }^{(12)}$ With sleep being recognised as being crucial to good health, researchers have begun to define the term 'sleep health'. According to Buysse, ${ }^{(13)}$ sleep health is a 'multidimensional pattern of sleep-wakefulness, adapted to individual, social and environmental demands, that promotes physical and mental well-being'. Buysse characterised good sleep health by the presence of 'subjective sleep satisfaction, appropriate sleep timing, adequate sleep duration, high sleep efficiency and sustained alertness during waking hours'.

\section{ADVERSE EFFECTS OF SLEEP DEPRIVATION}

The importance of sleep is also illustrated through the consequences of sleep deprivation. It is now well-known that sleep deprivation, apart from affecting physiological activity, can also affect mental functions. ${ }^{(14)}$ A study on the effect of sleep disruption showed that disrupted sleep is associated with DNA damage, which has been linked to the development of chronic medical diseases. ${ }^{(15)}$ Chronic sleep deprivation has been linked to hypertension, ${ }^{(16,17)}$ diabetes mellitus, ${ }^{(18)}$ hyperlipidaemia, ${ }^{(16,19)}$ obesity, and cardiovascular and cerebrovascular diseases. ${ }^{(20)}$ Long-standing sleep deprivation can contribute to emotional dysregulation and the development of mental disorders. ${ }^{(21)}$ For children and adolescents, studies have shown that inadequate or poor quality sleep in early childhood impairs socio-emotional and cognitive function via effects on the developing brain. ${ }^{(22,23)}$ There has also been greater appreciation of the complex and

${ }^{1}$ Department of Psychological Medicine, ${ }^{2}$ Department of Sleep Medicine, Surgery and Science, ${ }^{3}$ Department of Clinical Psychology, Changi General Hospital, ${ }^{4} \mathrm{Hougang}$ Polyclinic, National Healthcare Group Polyclinics, Singapore

Correspondence: Dr Hatta Santoso Ong, Associate Consultant Psychiatrist, Department of Psychological Medicine, Changi General Hospital, 2 Simei Street 3, Singapore 529889. hatta.santoso.ong@singhealth.com.sg 
bidirectional relationship between psychiatric disorders and sleep, in place of the traditional view that disordered sleep is merely a symptom of psychiatric disorders. Insomnia has been recognised as a risk factor for depression, anxiety and suicide. ${ }^{(24-26)}$ Sleep deprivation is also a well-known trigger for manic episodes in bipolar patients. ${ }^{(27)}$ In recognition of this, the International Society for Bipolar Disorders announced in 2019 that it has set up a Chronobiology Task Force to study the relationship between chronobiology and bipolar illness. ${ }^{(28)}$ A recent population-based study in Singapore ${ }^{(29)}$ found that poor sleep quality combined with short sleep duration (less than six hours a day) was associated with a higher chance of having any physical disorder and several mental disorders, such as major depressive disorder, bipolar disorder, generalised anxiety disorder and obsessive compulsive disorder.

Sleep deprivation has been linked to increased occupational errors, ${ }^{(30)}$ industrial accidents ${ }^{(31,32)}$ and motor vehicle accidents. ${ }^{(33-35)}$ This is likely a result of impaired attention, slowed reaction times and impaired judgement that follow lack of sleep. Chronic sleep deprivation has also been associated with increased work absenteeism. ${ }^{(36,37)}$ Hence, it is clear that chronic sleep deprivation is also a public health burden that can incur significant direct and indirect healthcare costs.

\section{SLEEP HEALTH INTERVENTIONS IN THE COMMUNITY}

As the world becomes more aware of chronobiology and the importance of sleep, some places in the world have started to introduce changes to school and work schedules in order to better align them to the natural human sleep-wake cycle. Bad Kissingen, a town in Germany, has set a goal to become the first 'ChronoCity' in the world. ${ }^{(38)}$ Its residents have managed to weave the principles of chronobiology into their daily life. Schools start later in the day and businesses are encouraged to offer flexitime. This allows people to work and study when they feel at their best. In the United States, researchers from the University of Minnesota observed an improvement in school attendance, as well as in students' engagement, focus and motivation, after delaying the start time for several high schools. ${ }^{(38)}$ The medical fraternity has also started to take notice. In 2014, the American Academy of Pediatrics issued a position statement that supported a school starting time of 8.30 am or later. ${ }^{(39)}$ This was followed by a similar recommendation by the American Academy of Sleep Medicine (AASM) in 2017. ${ }^{(40)}$ In 2015, the AASM and the National Sleep Foundation also updated their recommended daily sleep duration, which differs across age groups: $7-9$ hours for adults, 8-10 hours for teenagers, 9-11 hours for children aged 6-13 years, and 10-13 hours for children aged $3-5$ years. ${ }^{(41,42)}$

Singaporeans have been consistently found to be one of the most sleep-deprived populations in the world. ${ }^{(43,44)}$ A 2016 study on 350 individuals in Singapore showed that $44 \%$ of them had inadequate sleep (less than seven hours) on weekdays and $26 \%$ of them had inadequate sleep (less than seven hours) on weekends. ${ }^{(4)}$ Given the evidence-based adverse effects of sleep deprivation on physical and mental health, we believe there is an urgent need to pursue the introduction of community-based sleep health interventions in Singapore. This would include sleep education and promotion of sleep hygiene, adopting practices that reduce social jetlag and improve sleep health, and enhancing screening and treatment of sleep disorders.

\section{Educate the public about sleep and promote sleep hygiene}

Public education about the human chronobiology and the importance of sleep is required to foster a paradigm shift in the community's stance on sleep. This is especially important in Singapore, home to one of the world's most competitive economies, ${ }^{(46)}$ where an 'always-on' culture is pervasive and seen as highly desirable. A nationwide health promotion drive providing information on the benefits of sleep, as well as the negative consequences of sleep deprivation on physical and mental health, could help to raise awareness among the general population. Promotion of sleep hygiene could also improve sleep among the population. Sleep hygiene includes a variety of habits and practices that are necessary to have a good night's sleep and daytime alertness, such as maintaining a regular sleep schedule, having a relaxing routine before going to bed, avoiding heavy meals near bedtime and avoiding excessive light stimulation before bedtime. Nocturnal exposure to blue-wavelength light emitted from multimedia screens has the ability to modify our circadian rhythm and sleep. ${ }^{(47-50)}$ The widespread use of portable electronic devices, such as smartphones and handheld tablets, in the bedroom has been associated with sleep problems such as later bedtimes, ${ }^{(51)}$ shorter sleep duration, ${ }^{(51-54)}$ longer sleep latency ${ }^{(52,55)}$ and reduced sleep efficiency. ${ }^{(56)}$ Given that the majority of Singaporeans own a smartphone or a handheld tablet, ${ }^{(57)}$ public education and the promotion of healthy screen habits could help to improve sleep hygiene and sleep health in the population. The components of sleep hygiene education ${ }^{(58-61)}$ are summarised in Box 1.

Integration of sleep-related content into the educational curricula of all age groups would be helpful in inculcating good sleep hygiene habits from a young age. Workplace educational programmes focused on sleep hygiene and fatigue management have been shown to improve sleep duration, sleep quality and self-reported sleepiness complaints. ${ }^{(62)}$ Having similar programmes in Singapore could hence benefit the working population to achieve better sleep health while fulfilling their work commitments. Primary care physicians could play the role of an educator by imparting good sleep hygiene advice to patients with sleep difficulties. These interventions would help to create and sustain a broad societal commitment to engaging in proper sleep habits as a primary tenet of health.

\section{Adopt practices that reduce social jet lag and improve sleep health}

'Social jet lag' is a term coined by Roenneberg ${ }^{(63)}$ to describe the discrepancy between our individual circadian rhythm (biological time) and the external clock and timings that dictate our lives (social time). According to Roenneberg's research, ${ }^{(64)}$ the most 


\section{Box 1. Components of sleep hygiene education:}

Dos

- Maintain a sleep schedule; go to bed and wake up at the same time every day.

- Exercise for 30 minutes on most days of the week, but no later than 2-3 hours before bedtime.

- Increase exposure to bright light during daytime.

- Develop a relaxing routine before going to bed.

- Create a comfortable sleeping environment, such as a quiet, cool and dark room.

- Use the bedroom only for sleep and sex.

- If daytime naps are necessary, limit naps to no more than 30 minutes, to be taken before $3.00 \mathrm{pm}$.

\section{Don'ts}

- Avoid stimulants before bedtime e.g. caffeine, nicotine; some recommendations say 4-6 hours before bedtime.

- Avoid alcohol before bedtime.

- If possible, avoid other medications that may disrupt sleep,

e.g. diuretics. Discuss this with your doctor.

- Avoid heavy meals 2-3 hours before bedtime.

- Avoid night-time light exposure from electronic devices before bedtime, e.g. watching television programmes, using mobile phones in bed.

frequent chronotype sleeps from about midnight to $8.00 \mathrm{am}$. In Singapore, however, most schools start at 8.00 am and require the student to be awake by 6.00 am to arrive on time. Most workplaces also start the day at 8.30-9.00 am, requiring working adults to wake up at around 7.00 am or earlier in order to navigate the morning commute and reach their workplaces on time. Hence, for many children, adolescents and adults, their biological time and social time are in a state of perpetual desynchrony.

It is often postulated that developmental shifts in sleep physiology and academic pressures in Singapore reduce the typical sleep of adolescents on a school night. ${ }^{(65,66)}$ Delaying school start time to 8.30 am or later could reduce social jet lag among children and adolescents. This small change would reduce sleep curtailment experienced by most students and potentially benefit their physical and mental well-being. In a study conducted by Lo et $\mathrm{al}^{(67)}$ a school in Singapore implemented a 45-minute delay in school start time - from 7.30 am to 8.15 am. After one month, the students demonstrated improvements in sleep, alertness and mental well-being. These positive changes were maintained at nine months as well. Re-evaluation of the scheduling of co-curricular activities and regulation of the amount of homework assigned to students would also facilitate the practice of good sleep hygiene, as students would be able to have an early evening dinner, complete their homework, and have adequate time to unwind and relax before bedtime.

The introduction of flexitime at the workplace could improve sleep health among the working population. Flexitime usually refers to a schedule that allows employees to choose their starting and finishing times daily, as long as they complete a stipulated number of working hours. There are many benefits of flexitime that could impact mental health directly or indirectly. Employees could choose the time of the day to start work depending on their chronotype, so that it coincides with the time they feel most alert and productive. Flexitime could also enable employees to meet their personal responsibilities, for example, fetching their children to and from school. This arrangement would help employees balance their work and personal lives better, resulting in reduced stress levels and potentially increased productivity and motivation at work. It is thus heartening to read that in 2019, the Ministry of Manpower, Singapore, reported that more companies in Singapore were offering flexible work arrangements to employees. ${ }^{(68)}$ The Work-Life Grant, which provides funding support to companies that implement flexible work arrangements, received a boost in 2019 when the government added SGD 70 million to its budget in order to encourage more companies to offer flexible work arrangements for their employees. ${ }^{(69)}$ These initiatives were introduced with the aim of improving work-life balance. The incorporation of 'achieving better sleep health' as another objective behind these initiatives would help to underscore the importance of sleep health.

In France, there is a 'right to disconnect' law that bars employers and employees alike from sending work-related emails and text messages after office hours. ${ }^{(70)}$ A similar policy could be beneficial to sleep health in the local working population. Instead of being encumbered with work-related concerns in the period leading up to bedtime, working individuals could use the time after work to exercise and unwind in preparation for a good night's sleep.

Given that exposure to light-dark patterns is one of the main environmental cues for the circadian rhythm, poorly designed workspaces that do not allow adequate natural lighting could upset the individual's sleep-wake cycle and contribute to poor nocturnal sleep. Fluorescent lights used in some workspaces do not emit the luminous intensity seen in natural daylight and hence do not have the same effect on the circadian rhythm as natural daylight. Blue-enriched light-emitting diodes, on the other hand, can mimic the intensity and spectrum of natural daylight, and has been shown to improve subjective alertness, performance and evening fatigue. ${ }^{(71)}$ Some studies ${ }^{(62,72)}$ have shown that workplace environmental modifications, such as access to windows and daylight exposure, are associated with improved nocturnal sleep and daytime function. Designing workspaces with these considerations in mind could go a long way towards helping workers achieve better sleep health and improve work performance.

\section{Enhance screening and treatment of sleep disorders}

The primary care physician has an important role to play in the screening and treatment of sleep disorders. The chief benefit of physicians enquiring about sleep is early detection and treatment of sleep disorders. In addition, improvements in sleep may lead to improvements in other chronic medical conditions. ${ }^{(73-75)}$ Screening could be targeted at patient populations who are more susceptible to sleep difficulties, such as those with chronic medical conditions, chronic pain or other mental illnesses. In the elderly, research has shown that sleep patterns change with normal ageing independent of medical comorbidities and medications, such as reduced nocturnal sleep duration, 
reduced sleep efficiency, reduced slow-wave sleep and increased nocturnal awakenings. ${ }^{(76-80)}$ Patients who are overweight are at higher risk of sleep-related breathing disorders such as obstructive sleep apnoea ${ }^{(81-83)}$ as well as chronic insomnia, ${ }^{(84)}$ while patients who work shifts or irregular hours are at risk of shift work sleep disorder. ${ }^{(85)}$ Primary care physicians could include screening questions about sleep in their conversations with these higherrisk patients, asking open-ended questions such as, 'How is your sleep?' or 'How many hours of sleep do you get on a typical night?' These questions help to screen for patients with sleep difficulties; a more detailed sleep history can be taken from the patient. Historytaking for sleep would include questions pertaining to sleep habits and symptoms suggestive of a sleep-wake disorder, such as a parasomnia, breathing-related sleep disorder or circadian rhythm sleep-wake disorder. This would facilitate early referral of patients to a sleep medicine specialist.

Specific education and training strategies are also needed to increase awareness among healthcare professionals. Continuing medical education for primary care physicians on the topic of sleep and sleep disorders could increase their proficiency in sleep health management. Improved curriculum content and certification requirements for the training of sleep medicine, and the potential creation of sleep medicine as a new medical subspecialty, would expand local capabilities in treatment and research of sleep disorders.

\section{CONCLUSION}

Sleep medicine is a rapidly evolving field that has led to an increased understanding of human chronobiology and an increased recognition of the importance of sleep health. While there has been a wealth of new research findings, little of this knowledge has been translated into practical changes that can be introduced into daily life to improve sleep health. However, other countries that implemented various sleep health interventions have reported promising results, and similar interventions could bring about positive changes to sleep health in the local community.

\section{REFERENCES}

1. Lack LC, Wright HR. Chronobiology of sleep in humans. Cell Mol Life Sci 2007; 64:1205-15.

2. Borbély AA. A two process model of sleep regulation. Hum Neurobiol 1982; 1:195-204.

3. Borbély AA, Daan S, Wirz-Justice A, Deboer T. The two-process model of sleep regulation: a reappraisal. J Sleep Res 2016; 25:131-43.

4. Aschoff J. Exogenous and endogenous components in circadian rhythms. Cold Spring Harb Symp Quant Biol 1960; 25:11-28.

5. Goel N, Basner M, Rao H, Dinges DF. Circadian rhythms, sleep deprivation, and human performance. Prog Mol Biol Transl Sci 2013; 119:155-90.

6. Fisher SP, Foster RG, Peirson SN. The circadian control of sleep. In: Kramer A, Merrow M, eds. Handbook of Experimental Pharmacology. Berlin, Heidelberg: Springer, 2013: 153-83.

7. Fernandez-Mendoza J, Calhoun S, Bixler EO, et al. Insomnia with objective short sleep duration is associated with deficits in neuropsychological performance: a general population study. Sleep 2010; 33:459-65.

8. Lowe CJ, Safati A, Hall PA. The neurocognitive consequences of sleep restriction: a meta-analytic review. Neurosci Biobehav Rev 2017; 80:586-604.

9. Lim J, Dinges DF. A meta-analysis of the impact of short-term sleep deprivation on cognitive variables. Psychol Bull 2010; 136:375-89.

10. Irwin MR. Why sleep is important for health: a psychoneuroimmunology perspective. Annu Rev Psychol 2015; 66:143-72.

11. Adam K. Sleep as a restorative process and a theory to explain why. Prog Brain
Res 1980; 53:289-305.

12. Iliff JJ, Nedergaard M. Is there a cerebral lymphatic system? Stroke 2013; 44(6 Suppl 1):S93-5.

13. Buysse DJ. Sleep health: can we define it? Does it matter? Sleep 2014; 37:9-17.

14. Freeman D, Sheaves B, Goodwin GM, et al. The effects of improving sleep on mental health (OASIS): a randomised controlled trial with mediation analysis. Lancet Psychiatry 2017; 4:749-58.

15. Cheung V, Yuen VM, Wong GTC, Choi SW. The effect of sleep deprivation and disruption on DNA damage and health of doctors. Anaesthesia 2019; 74:434-40.

16. Cappuccio FP, Miller MA. Sleep and cardio-metabolic disease. Curr Cardiol Rep 2017; 19:110.

17. Meng L, Zheng Y, Hui R. The relationship of sleep duration and insomnia to risk of hypertension incidence: a meta-analysis of prospective cohort studies. Hypertens Res 2013; 36:985-95.

18. Green MJ, Espie CA, Popham F, Robertson T, Benzeval M. Insomnia symptoms as a cause of type 2 diabetes incidence: a 20 year cohort study. BMC Psychiatry 2017; 17:94.

19. Kruisbrink M, Robertson W, Ji C, et al. Association of sleep duration and quality with blood lipids: a systematic review and meta-analysis of prospective studies. BMJ Open 2017; 7:e018585.

20. Yin J, Jin X, Shan Z, et al. Relationship of sleep duration with all-cause mortality and cardiovascular events: a systematic review and dose-response meta-analysis of prospective cohort studies. J Am Heart Assoc 2017; 6:e005947.

21. Saghir Z, Syeda JN, Muhammad AS, Balla Abdalla TH. The amygdala, sleep debt, sleep deprivation, and the emotion of anger: a possible connection? Cureus 2018; 10:e2912.

22. Taveras EM, Rifas-Shiman SL, Bub KL, Gillman MW, Oken E. Prospective study of insufficient sleep and neurobehavioral functioning among school-age children. Acad Pediatr 2017; 17:625-32.

23. Touchette E, Petit D, Séguin JR, et al. Associations between sleep duration patterns and behavioral/cognitive functioning at school entry. Sleep 2007; 30:1213-9.

24. Baglioni C, Battagliese G, Feige B, et al. Insomnia as a predictor of depression: a meta-analytic evaluation of longitudinal epidemiological studies. J Affect Disord 2011; 135:10-9.

25. Li L, Wu C, Gan Y, Qu X, Lu Z. Insomnia and the risk of depression: a metaanalysis of prospective cohort studies. BMC Psychiatry 2016; 16:375.

26. Pigeon WR, Bishop TM, Krueger KM. Insomnia as a precipitating factor in new onset mental illness: a systematic review of recent findings. Curr Psychiatry Rep 2017; 19:44.

27. Wehr TA, Sack DA, Rosenthal NE. Sleep reduction as a final common pathway in the genesis of mania. Am J Psychiatry 1987; 144:201-4.

28. International Society for Bipolar Disorders. Active task forces. Available at: https://www.isbd.org/active-task-forces. Accessed March 18, 2020.

29. Seow LSE, Tan XW, Chong SA, et al. Independent and combined associations of sleep duration and sleep quality with common physical and mental disorders: results from a multi-ethnic population-based study. PLoS One 2020; 15:e0235816.

30. Ulmer C, Wolman DM, Johns MME. Resident Duty Hours: Enhancing Sleep, Supervision, and Safety. Washington, DC: National Academies Press, 2009.

31. Léger D, Guilleminault C, Bader G, Lévy E, Paillard M. Medical and socioprofessional impact of insomnia. Sleep 2002; 25:625-9.

32. Uehli K, Mehta AJ, Miedinger D, et al. Sleep problems and work injuries: a systematic review and meta-analysis. Sleep Med Rev 2014; 18:61-73.

33. Garbarino S, Nobili L, Beelke M, De Carli F, Ferrillo F. The contributing role of sleepiness in highway vehicle accidents. Sleep 2001; 24:203-6.

34. Garbarino S, Magnavita N, Guglielmi O, et al. Insomnia is associated with road accidents. Further evidence from a study on truck drivers. PLoS One 2017; 12:e0187256.

35. Colten H, Altevogt B, eds. Sleep Disorders and Sleep Deprivation: An Unmet Public Health Problem. Washington, DC: National Academies Press, 2006.

36. Daley M, Morin CM, LeBlanc M, et al. Insomnia and its relationship to healthcare utilization, work absenteeism, productivity and accidents. Sleep Med 2009; 10:427-38

37. Leigh JP. Employee and job attributes as predictors of absenteeism in a national sample of workers: the importance of health and dangerous working conditions. Soc Sci Med 1991; 33:127-37.

38. Geddes L. Why we should be watching the sun, not the clock. In: The Guardian [online]. Available at: https://www.theguardian.com/news/2019/ jan/11/watching-the-sun-not-the-clock-sleep-body-clocks-daylight-saving-time. Accessed March 18, 2020.

39. Adolescent Sleep Working Group; Committee on Adolescence; Committee on School Health. School start times for adolescents. Pediatrics 2014; 134:642-9.

40. Watson NF, Martin JL, Wise MS, et al. Delaying middle school and high school start times promotes student health and performance: an American Academy of Sleep Medicine position statement. J Clin Sleep Med 2017; 13:623-5.

41. Hirshkowitz M, Whiton K, Albert SM, et al. National Sleep Foundation's updated sleep duration recommendations: final report. Sleep Health 2015; 1:233-43.

42. Watson NF, Badr MS, Belenky G, et al. Recommended amount of sleep for a 
healthy adult: a joint consensus statement of the American Academy of Sleep Medicine and Sleep Research Society. Sleep 2015; 38:843-4.

43. Ho K. Four in ten Singaporeans not getting enough sleep. In: YouGov.sg [online]. Available at: https://sg.yougov.com/en-sg/news/2018/12/11/four-tensingaporeans-not-getting-enough-sleep/. Accessed March 25, 2020.

44. The global pursuit of better sleep health. Available at: https://www.usa.philips. com/c-dam/b2c/master/experience/smartsleep/world-sleep-day/2019/2019philips-world-sleep-day-survey-results.pdf. Accessed March 25, 2020.

45. Tan NC, Tan MS, Hwang SW, et al. Sleep time and pattern of adult individuals in primary care in an Asian urbanized community: a cross-sectional study. Medicine (Baltimore) 2016; 95:e4749.

46. Aw CW. Singapore economy ranked world's most competitive. The Straits Times 2019 Oct 10. Available at: https://www.straitstimes.com/business/economy/ singapore-economy-ranked-worlds-most-competitive. Accessed April 8, 2020

47. Cajochen C. Alerting effects of light. Sleep Med Rev 2007; 11:453-64.

48. Cajochen C, Münch M, Kobialka S, et al. High sensitivity of human melatonin, alertness, thermoregulation, and heart rate to short wavelength light. J Clin Endocrinol Metab 2005; 90:1311-6.

49. van der Lely S, Frey S, Garbazza C, et al. Blue blocker glasses as a countermeasure for alerting effects of evening light-emitting diode screen exposure in male teenagers. J Adolesc Health 2015; 110:1432-8.

50. Shechter A, Kim EW, St-Onge MP, Westwood AJ. Blocking nocturnal blue light for insomnia: a randomized controlled trial. J Psychiatr Res 2018; 96:196-202.

51. Li S, Jin X, Wu S, et al. The impact of media use on sleep patterns and sleep disorders among school-aged children in China. Sleep 2007; 30:361-7.

52. Hysing M, Pallesen S, Stormark KM, et al. Sleep and use of electronic devices in adolescence: results from a large population-based study. BMJ Open 2015; 5:e006748.

53. Falbe J, Davison KK, Franckle RL, et al. Sleep duration, restfulness, and screens in the sleep environment. Pediatrics 2015; 135:e367-75.

54. Carter B, Rees P, Hale L, Bhattacharjee D, Paradkar MS. Association between portable screen-based media device access or use and sleep outcomes a systematic review and meta-analysis. JAMA Pediatr 2016; 170:1202-8.

55. Alexandru G, Michikazu S, Shimako H, et al. Epidemiological aspects of selfreported sleep onset latency in Japanese junior high school children. J Sleep Res 2006; 15:266-75.

56. Fobian AD, Avis K, Schwebel DC. Impact of media use on adolescent sleep efficiency. J Dev Behav Pediatr 2016; 37:9-14.

57. Digital 2020: Singapore. In: Datareportal [online]. Available at: https:// datareportal.com/reports/digital-2020-singapore. Accessed October 7, 2020.

58. Reeve K, Bailes B. Insomnia in adults: etiology and management. J Nurse Pract 2010; 6:53-60.

59. Tanzi M, Lodolce AE, Prasad B. Management of insomnia: considerations for patients with chronic pain. Pract Pain Manag 2011; 11. Available at: https:// www.practicalpainmanagement.com/pain/other/co-morbidities/managementinsomnia-considerations-patients-chronic-pain. Accessed April 11, 2020

60. U.S. Department of Health and Human Service. In brief: your guide to healthy sleep. Available at: www.nhlbi.nih.gov/health/public/sleep/healthysleepfs.pdf. Accessed April 11, 2020.

61. Sleep matters: get the answers to common sleep conditions. In: Singhealth Healthy Living Series. Available at: https://www.singhealth.com.sg/patient-care/ patient-education/Documents/sleep-conditions-singhealth.pdf. Accessed April 12,2020

62. Redeker NS, Caruso CC, Hashmi SD, et al. Workplace interventions to promote sleep health and an alert, healthy workforce. J Clin Sleep Med 2019; 15:649-57.

63. Roenneberg T, Wirz-Justice A, Merrow M. Life between clocks: daily temporal patterns of human chronotypes. J Biol Rhythms 2003; 18:80-90.

64. Roenneberg T. Worlds Apart. In: Roenneberg T. Internal Time: Chronotypes, Social Jet Lag, and Why You're So Tired. Cambridge, UK: Harvard University
Press, 2012: 8-15.

65. Beebe DW. The cumulative impact of adolescent sleep loss: next steps. Sleep 2016; 39:497-9.

66. Owens J, Adolescent Sleep Working Group; Committee on Adolescence. Insufficient sleep in adolescents and young adults: an update on causes and consequences. Pediatrics 2014; 134:e921-32.

67. Lo JC, Lee SM, Lee XK, et al. Sustained benefits of delaying school start time on adolescent sleep and well-being. Sleep 2018; 41:zsy052.

68. Sim F. More companies offering flexible work arrangements: MOM report. In: Channel NewsAsia 2019 Jan 16. Available at: https://www.channelnewsasia. com/news/singapore/manpower-flexible-work-arrangement-annual-leavereport-11128916. Accessed April 2, 2020.

69. Abu Baker J. Scheme to encourage flexi-work arrangements gets $\$ \$ 70$ million boost. In: Channel NewsAsia 2019 Mar 5. Available at: https://www. channelnewsasia.com/news/singapore/scheme-encourage-flexi-workarrangements-budget-70-million-boost-11313340. Accessed April 2, 2020.

70. Morris DZ. New French law bars work email after hours. In: Fortune [online]. Available at: https://fortune.com/2017/01/01/french-right-to-disconnect-law/. Accessed April 7, 2020.

71. Viola AU, James LM, Schlangen LJM, Dijk DJ. Blue-enriched white light in the workplace improves self-reported alertness, performance and sleep quality. Scand J Work Environ Health 2008; 34:297-306.

72. Boubekri M, Cheung IN, Reid KJ, Wang CH, Zee PC. Impact of windows and daylight exposure on overall health and sleep quality of office workers: a casecontrol pilot study. J Clin Sleep Med 2014; 10:603-11.

73. Grandner MA, Malhotra A. Sleep as a vital sign: why medical practitioners need to routinely ask their patients about sleep. Sleep Health 2015; 1:11-2.

74. Roth T, Price JM, Amato DA, et al. The effect of eszopiclone in patients with insomnia and coexisting rheumatoid arthritis: a pilot study. Prim Care Companion J Clin Psychiatry 2009; 11:292-301.

75. Vitiello MV, Rybarczyk B, Von Korff M, Stepanski EJ. Cognitive behavioral therapy for insomnia improves sleep and decreases pain in older adults with co-morbid insomnia and osteoarthritis. J Clin Sleep Med 2009; 15:355-62.

76. Foley D, Ancoli-Israel S, Britz P, Walsh J. Sleep disturbances and chronic disease in older adults: results of the 2003 National Sleep Foundation Sleep in America Survey. J Psychosom Res 2004; 56:497-502.

77. Ohayon MM, Carskadon MA, Guilleminault C, Vitiello MV. Meta-analysis of quantitative sleep parameters from childhood to old age in healthy individuals: developing normative sleep values across the human lifespan. Sleep 2004; 27:1255-73

78. Espiritu JRD. Aging-related sleep changes. Clin Geriatr Med 2008; 24:1-14.

79. Vitiello MV. Sleep in normal aging. Sleep Med Clin 2012; 7:539-44.

80. Li J, Vitiello MV, Gooneratne NS. Sleep in normal aging. Sleep Med Clin 2018; 13:1-11.

81. Calvin AD, Albuquerque FN, Lopez-Jimenez F, Somers VK. Obstructive sleep apnea, inflammation, and the metabolic syndrome. Metab Syndr Relat Disord 2009; 7:271-8.

82. Tuomilehto H, Seppä J, Uusitupa M. Obesity and obstructive sleep apnea-clinical significance of weight loss. Sleep Med Rev 2013; 17:321-9.

83. Ong CW, O'Driscoll DM, Truby H, Naughton MT, Hamilton GS. The reciprocal interaction between obesity and obstructive sleep apnoea. Sleep Med Rev 2013; 17:123-31

84. Pearson NJ, Johnson LL, Nahin RL. Insomnia, trouble sleeping, and complementary and alternative medicine: analysis of the 2002 National Health Interview Survey data. Arch Intern Med 2006; 166:1775-82.

85. Cheng WJ, Cheng Y. Night shift and rotating shift in association with sleep problems, burnout and minor mental disorder in male and female employees. Occup Environ Med 2017; 74:483-8

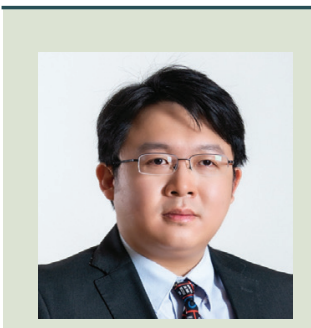

About the First Author

Dr Hatta Santoso Ong is an Associate Consultant Psychiatrist at the Department of Psychological Medicine and the Department of Sleep Medicine, Surgery and Science at Changi General Hospital, Singapore. He treats a variety of conditions, including mood and anxiety disorders, psychotic disorders, sleep disorders and addiction disorders. His academic appointments include Clinical Instructor, Duke-NUS Medical School, and Clinical Lecturer, Yong Loo Lin School of Medicine, National University of Singapore. He is also a Physician Faculty Member for the SingHealth Family Medicine Residency Programme. 